\title{
Maternal and Fetal Outcome of Grandmultipara in Comparison to Multiparous Woman in Two hospital in Khartoum State
}

\author{
Dr Isamaldin Alamin Mohmed Ahmed MBBS.MD.DOWH \\ Obstetrics and Gynaecology, Sudan Medical Specialization Board, Sudan
}

\begin{abstract}
:
Aims and Objectives: To compare the incidence of feto-maternal complications of pregnancy and labor between grandmultiparas and multiparous women.

Material and Methods: This prospective study was carried out in the Departments of Obstetrics and Gynaecology in two hospitals in Khartoum state (Omdurman Maternity Hospital, and Khartoum North Teaching Hospital), in the period from January 2010 to June 2010. A total of 450 deliveries in the two hospital were divided in two groups (150 grandmultiparas and 300 multiparas) in whom the maternal and fetal outcomes were analyzed and compared.

Results: It was found that in the GMPs there were increase in age more than 35 years $38 \%$ vs $9 \%(p<0.05)$, lower socioeconomic class $48 \%$ vs $28.7 \%$, $(p<0.05)$, incidence of hypertensive disorder of pregnancy $30.0 \% \mathrm{vs}$ $13.7 \%(p<0.05)$, diabetes mellitus $8 \%$ vs $3 \%(p<0.05)$. anemia $28.7 \%$ vs $12.7 \%(p<0.05)$, multiple pregnancy $8.0 \%$ vs $3.3 \%(p<0.05)$, breech presentation $9.4 \%$ vs $5.5 \%, \quad(p<0.05)$, transverse lie $3.6 \%$ vs. $0.3 \%$ $(p>0.05)$, preterm labour 16.0 vs. $12.7 \%$ ( $p>0.05)$, overall APH $8.7 \%$ vs $5.7 \%(p<0.05)$, and Macrosomic babies $18.8 \%$ vs $5.8 \%(p>0.05)$, and SVD $76.7 \%$ vs $60.3 \%$ ( $p<0.05)$.

there was a decreased incidence in induction of labour $2 \%$ vs $11.0 \%(p<0.05)$, instrumental delivery $6 \% v s$ $12 \%$, ( $p<0.05)$, Em C/S 17.3\% vs 27.7\%,(p<0.05), overall PPH $8.0 \%$ vs 9.0\%, (p>0.05), LBW $7.2 \%$ vs $11.0 \%$, the $(p<0.05)$ and maternal mortality $0.7 \%$ vs $1 \%(p>0.05$

Other than birth weight, there was no significant differences in fetal outcomes, we found that, still birth $10.1 \%$ vs $10.0 \%$ and babies distressed $3.2 \%$ vs $4.2 \%$.
\end{abstract}

Keyword: grandmultipara, multiparous, maternal outcome, fetal outcome, placenta previa, abrubtio placentae, caesarean section.

\subsection{Definition}

\section{Introduction}

The International Federation of Gynaecology and obstetrics 1993 defined grandmultiparity as the delivery of fifth to ninth, whereas women who are undergoing their tenth or more deliveries considered to be great-grandmultiparaes.[8].

King et al, and Toohey et al, considered grandmultiparae to be women who gave birth to five or more previous deliveries[2,7]. (definition which we used in this study).

For a pregnancy to count as a "birth", it must go to at least 24 weeks gestation or yield an infant that weighs at least 500 grams, irrespective of whether the infant is live born or not. $\{26\}$.

In his 1934 article[1], entitled 'The dangerous multiparae', Bethel Solomons wrote: "my main object is to remove if possible once and for all, the idea that a primigravida means a difficult labour but a multiparae means an easy one, It is altogether a mistake to suppose that in childbearing practice makes perfect".

Solomons' concern for the multiparae was prompted by a study at the time from the Department of Health for Scotland which showed the maternal mortality rate associated with multiparity increasing "steadily and speedily". from the fifth pregnancy until women bearing their tenth child or more; had a mortality rate five times as high as all women bearing children.

Since that time a number of studies have been reported from various parts of the world investigating the role of high parity on perinatal outcome. $[1,4.36,19,18,42]$.

Pregnancy after fifth delivery is viewed with anxiety, especially by obstetricians in developing countries working under difficult conditions and with limited facilities. The complications that occur to these patients during pregnancy, at the time of delivery, and in the perperium warrants them special respect, first of all the ordinary complications of pregnancy and child birth are increased in this group of women, secondly, since such complications tend to be more common in the lower socioeconomic groups, their ill-effects have a far reaching impact on the patients affected due to poverty, lack of facilities and the usual accompanying delayed presentation to medical personnel. Moreover, these patients usually lack medical education, they are undernourished and almost always overworked, with usually poor antenatal care.[4,5,6,42]. 
increasing cognizance has been taken of grandmultiparity as a clinical entity in its own right. These patients are liable to a series of dramatic complications, all the more dangerous because they are often unsuspected.

Since most highly parous women are above the age of 35, these women are more prone to develop complications such as diabetes, hypertension, anemia, and chronic renal disease which complicate their ongoing pregnancies even more as opposed to the younger patients who are usually free of such complications.

Intrapartum complications that are classically associated with grand multiparas include fetal malpresentations, dysfunctional labour, hypertensive disease, anemia, placenta previa, retained placenta, uterine rupture, abruptio placentae, post partum haemorrhage and macrosomic babies.

Other general conditions which are part of the normal process of ageing are liable likewise to intrude themselves upon the clinical picture, obesity, which is often gross in these cases, increases the dangers of child bearing, as is well known, and not the least reason for this is the difficulty of making an accurate examination.

Sociological factors play a very important part, for, the majority of these patients are poor, overworked and tired, many of them have never fully regained a good blood picture, and anemia may dog them from one pregnancy to the next without respite, they tend to feed their numerous children at the expense of their own nutrition, so that they are consequently often very short of vitamins and first class proteins, they are too busy to attend to their health, and due to the rapid succession of pregnancies and periods of lactation they are likely to become depleted from calcium..[6,36,37,19,18].

Although grandmultiparity has long been considered an obstetric complication for both mother and fetus recent studies indicated that, with proper perinatal care, women with high-parity rates are no longer at high risk.

in March 2002 the British Journal of Obstetrics and Gynaecology published a new study of grandmultiparae in the UK. The authors concluded that: in a developed country with satisfactory health care conditions, grandmultiparity should not be considered dangerous, and risk assessment should be based on past and present history and not simply on the basis of parity, so the controversy concerning the risk of grandmultiparity can be somewhat resolved in countries where obstetrics is uniformly practiced at modern level of excellence where almost all pregnancies are followed in antenatal outpatient clinics, and deliveries are carried out in well equipped medical centers.[9].

Nordin N.M. in his study Is grandmultiparity a significant risk factor in this new millennium, With adequate care, the maternal fetal outcome of grandmutiparous women is good and comparable to the multiparous women. ${ }^{(45)}$.

Shah P.S. conclude that grand multiparity and great grand multiparity were not associated with increased risk of pregnancy outcomes[20].

\subsection{RISK FACTORS}

\section{Literature Review}

\subsubsection{Age}

Advanced maternal age is an important factor that contributes to adverse maternal outcome and can be associated with high parity.

Hecht-Resnick R, Harel found that the age of the grandmultiparas was significantly higher compared with the control groups, which may explain the higher incidence among them of antenatal medical disorders, such as diabetes mellitus and hypertensive disease ${ }^{[11]}$.

Maymon E, Ghezzi $\mathrm{F}$ assess the importance of birth order and advanced maternal age on peripartum complications he found that Higher birth order remained an independent risk factor for peripartum complications after adjustment for maternal age ${ }^{[13]}$.

\subsubsection{SOCIO ECONOMIC STATUS}

Since high parities tend to be more common in the lower socioeconomic groups who have low income this leads to affect nutritional and health status of these mothers and with no facilities to contact health centre and family planning services.

Nassar A.H.found that Grandmultiparity was associated with a low socioeconomic status ${ }^{[43]}$.

Mor-Yosef et al in his survey which covers 22,815 deliveries in a 3 month period, the 1542 grandmultiparous women were divided into two groups: low socioeconomic group (947) and high socioeconomic group (595). Perinatal mortality and low birth weight were found to be in correlation with low socioeconomic status but not with grand multiparity. Maternal diseases complicating pregnancy were found to be significantly more common for grand multipara for both socioeconomic groups ${ }^{[18]}$.

Both Toohey et al ${ }^{[7]}$ and King et al. ${ }^{[21]}$ reported highly favorable outcomes in a group of women with low socio-economic status so the effect of the socioeconomic status on perinatal outcome need to be evaluated. 


\subsection{Antepartum and Intrapartum Complications}

\subsubsection{Hypertensive disorders}

Hypertensive disorders of pregnancy are common complication it include:

Pregnancy induced hypertension which occurs in around 16-24\% of first pregnancies and 12-15\%of subsequent pregnancies, pre-eclampsia [PE] which complicates 3-5\% of first pregnancies and $1 \%$ of subsequent pregnancies with around $5-10 \%$ of cases being sever, chronic hypertension [CHT] is present in $2-4 \%$ of pregnant women, over $90 \%$ of cases are due to essential hypertension, and these women tend to be older and heavier with a family history of hypertension ${ }^{[25]}$.

In a series of 1567 deliveries over 10 years in the same hospital in Oulu, Finland, Vehaskari A et al, reported the special obstetric characteristics of grand multiparas (GMs) and the extent to which the parturient age affected the incidence of complications, differences were noted between the obstetric behavior of GMs as compared with other parturients. Hypertensive disease was distinctly more frequent among GMs than among the other parturients ${ }^{[12]}$.

\subsubsection{Diabetes mellitus}

The WHO has defined diabetes mellitus as either a raised fasting blood glucose level of $>7.8 \mathrm{mmol} / 1$ or a level of $11.1 \mathrm{mmol} / 1$ 1-2hours following a 75 grams glucose load. The importance of good glycaemic control during pregnancy is reinforced by the direct relationship between blood glucose levels and the incidence of fetal and maternal complications.[23].

Nassar A.H.found that Grandmultiparas had $\sim 2$-fold increased risk of gestational diabetes. ${ }^{[43]}$.

Goldman GF et al in his case control study found that, the age of grand multipara was significantly higher which may explain the higher incidence among them of antenatal medical disorders such as diabetes mellitus and hypertensive disorders [11].

\subsubsection{Anaemia}

The WHO recommends that the HB concentration should not fall below $11 \mathrm{~g} / \mathrm{dl}$ at any time during pregnancy, but many clinicians use the figure of $10.5 \mathrm{~g} / \mathrm{dl}$ as recommended by the centres for Disease Control of North America ${ }^{[26]}$.

Anaemia is one of the most frequently observed nutritional deficiencies in the world today. It is especially prevalent in women of reproductive age particularly during pregnancy, it is often a contributory cause of maternal morbidity and mortality. GMP and short birth interval is well documented as a risk factor of anaemia. This is because there is not enough interval between pregnancies for the women to replenish their iron stores .However, it is generally accepted that a women requires an interval of two to three years between births to recover physiologically from the effect of previous delivery ${ }^{[23]}$.

A matched cohort study in an inner city university maternity hospital in the United Kingdom, three hundred and ninety-seven grandmultiparous women were compared with three hundred and ninety-seven agematched multiparous women. Grandmultiparous women were significantly more likely to have a haemoglobin $<10 \mathrm{~g} / \mathrm{dL}$ antenatally than ordinary multiparous women ${ }^{[9]}$.

\subsubsection{Antepartum Haemorrhage (APH)}

APH: Bleeding from the birth canal after viability until the onset of labour. The major causes of APH are placenta praevia and placenta abruption.

In developing countries, today, wide spread pre-existing anaemia, difficulties with transportation and restricted medical facilities ensure that APH continues to be responsible for many maternal deaths, fetal loss is much more common than maternal death, $15 \%$ of perinatal deaths can be attributed to APH, notably from abruption $^{[25]}$.

In a series of 1567 deliveries over 10 years in the same hospital in Oulu, Finland, Vehaskari report the special obstetric characteristics of grand multiparas (GMPs) and the extent to which the parturient age affected the incidence of complications. Differences were noted between the obstetric behaviour of GMPs as compared with other parturient, found the frequency of abruptio placentae, placenta praevia, and retained placenta was significantly higher in GMPs. Although the difference was not statistically clear in this study, Abruptio placentae is affected both by high parity and age, while placenta praevia is independent of age and predisposed by high parity ${ }^{[12]}$.

Nassar A.H.found that Grandmultiparity was associated with a 3-fold increased risk of abruption; ${ }^{[43]}$. The incidence of antenatal and intrapartum complications and neonatal outcomes was compared G. J. Bugg et al found that there was no significant difference observed in the incidence of placental abruption, dysfunctional labour, malpresentation, or postpartum haemorrhage ${ }^{\mathrm{I}}{ }^{[9]}$.

A Babinski et al, studied One hundred thirty-three great-grand multiparas, 314 grand multiparas, and 2195 multiparas who were delivered of their infants between 1988 and 1998 for the study, and he found the 
incidence of postpartum hemorrhage, , placenta previa, was significantly higher in grand multiparas than in multiparas ${ }^{[8]}$.

F A Aziz et al, during the period 1975-1979 in the three major hospitals in Khartoum, Sudan, the study population consisted of 8858 patients who delivered in those hospitals; 3130 of them had five or more children. The obstetric complications and the fetal outcome were investigated, and comparisons were made between groups according to parity, there was a high rate of antenatal complications, such as anaemia, antepartum haemorrhage and postpartum haemorrhage, among the grand multiparous patients. The stillbirth rate and neonatal mortality were high ${ }^{[32]}$.

\subsubsection{Pattern of labour in GMPs}

Gurewitsch et al, in his retrospective cohorts study of spontaneously labouring, vertex-presenting, term, grand multiparous women (parity $>5$ ) from two medical centres over 5.5 years were matched randomly to nulliparous women and lower parity multiparous women controlled for age, hospital, and year of delivery. Descent curves for labour were modelled and the results were, GMP women maintain a higher station for a longer time before delivery compared with nulliparous women or P1-4 women but transition rapidly to delivery once full dilatation is reached. Higher station likely contributes to the slower progress of first-stage labour among GM women compared with P1-4 women. More important is the slower initial progress of either dilation or descent should not be considered abnormal for the GMP woman, and although high station is associated with both primary dysfunctional labour and secondary arrest of dilation in nulliparous women, this is not the case for multiparous women, as evidenced by the differences in operative delivery rates between these groups yet similar results in terms of perinatal outcome $\mathrm{e}^{[21]}$.

S.Arulkmara et al carried out study to see the effect of increased parity in uterine activity during labour, they studied 400 multipara including GMP of Chinese origin. The result was multiparus women with previous vaginal delivery seems more likely to have an easy labour due to easily progression in cervical dilatation, more efficient uterine contraction and reduced pelvic and cervical tissue resistance than those with low parity and prirnigravida ${ }^{[24]}$.

\subsubsection{Postpartum haemorrhage (PPH)}

Postpartum haemorrhage is defined as excessive bleeding from the genital tract following the delivery of the baby. The WHO defines primary PPH as bleeding in excess of $500 \mathrm{ml}$ in the first $24 \mathrm{~h}$ following delivery ,the main causes of primary PPH are failure of the uterus to contract effectively [atonic uterus] retention of placenta and membranes in the uterus and trauma to the genital tract ${ }^{[25]}$.

A case control study to determine the risk factors for primary PPH at Obafemi Awolowo University Hospital. The study consisted of 101 women who developed PPH after normal vaginal delivery and 107 women with normal unassisted vaginal delivery without PPH. The results showed significant relation ship with prolonged second and third stages of labour and non use of oxytocics after vaginal delivery. Previously hypothesized risk factors for PPH such as grand multiparity, primigravidity and previous episodes of PPH were not significantly associated with $\mathrm{PPH}{ }^{[27]}$.

In Nigeria 204 cases of primary PPH were studied compared with the same number of normally delivered cases, the result was; primary PPH occurs more frequent in PG and GMPs than multipara, with more occurrence in GMPs. The commonest cause was uterine atonia which attributed to mismanagement of third stage of labour also they add the mood of delivery and anaemia as contributing factors ${ }^{[28]}$

\subsubsection{Uterine Ruptures}

Rupture of the gravid uterus is one of the most serious obstetrical emergencies, carrying a high maternal morbidity and mortality with high rate of perinatal loss, associated with loss of future fertility due to performance of hysterectomy or repair with tubal ligation in some patient ${ }^{[29]}$.

Vadat A et al analyzed 150 cases of uterine ruptures in late pregnancy in 8 years duration, he found that; the common etiological factors were GMP, malpresentation and oxytocin hyperstimulation in labour in unscarred uterus, hysterectomy or repair with tubal ligation were performed to all cases with increase maternal morbidity and mortality ${ }^{[29]}$.

Matched cohort study was done in an inner city university maternity hospital in the United Kingdom. Three hundred and ninety-seven grandmultiparous women were compared with three hundred and ninety-seven age-matched multiparous women. The incidence of antenatal and intrapartum complications and neonatal outcome

G. J. Bugg found that overall, grandmultiparous women had an intrapartum complication incidence of $18 \%$, which was not significantly different from the $18 \%$ rate observed in the mtiltiparous group. There were no uterine ruptures or maternal deaths in either group [9]. 
In a series of 1567 deliveries over 10 years in the same hospital in Oulu, Finland, Vehaskari A et al reported the special obstetric characteristics of grand multiparas. The incidence of uterine rupture has been reported to be higher in GMPs than in other parturient, ${ }^{[12]}$,

\subsubsection{Other Complications}

G. J. Bugg et al found that Overall, grandmultiparous women had an intrapartum complication incidence of $16 \%$, which was not significantly different from the $18 \%$ rate observed in the multiparous group. There were no uterine ruptures or maternal deaths in either group. there was no significant difference in the incidence of emergency caesarean section $(7.0 \%$ vs. $8.3 \%)$ between the two groups ${ }^{191}$.

The case-notes and records of grandmultiparous patients delivered at the Lagos University Teaching Hospital between 1st January, 1994 and 31st December, 1996 were analyzed. The incidence of intrapartum complications, cephalopelvic disproportion, obstructed labour and Caesarean section, were found to be higher in the unbooked grandmultiparous patients ${ }^{{ }^{[10]}}$.

Hecht-Resnick et al examines the outcome of delivery in 1700 women in their fifth or more delivery, as compared with two control groups: 622 primiparas and 735 multiparas (two to three previous deliveries). No significant differences were found among the three groups for preterm or post-term births, small-for-gestationalage infants, polyhydramnios, oligohydramnios, perinatal death, fetal distress, multiple births, placenta previa, abruptio placentae or cord prolapse ${ }^{[11\}}$

In a series of 1567 deliveries over 10 years in the same hospital in Oulu, Finland, differences were noted between the obstetric behaviour of GMPs as compared with other parturient study showed that breech presentation to be less frequent among GMs. Vehaskari A et al, found the incidence of operative deliveries was roughly similar in both groups. Caesarean section, including repeat sections, was distinctly lower among GMPs; no difference appeared neither in the incidence of multiple pregnancies, nor in the incidence of prematurity ${ }^{[12]}$.

Babinski found the incidence of malpresentation at the time of delivery, anemia, preterm delivery, and meconium-stained amniotic fluid increased with higher parity, whereas the rate of caesarean delivery decreased The incidence of pre eclampsia, , macrosomia, postdate pregnancy, and low apgar scores was significantly higher in grand multiparas than in multiparas, whereas the proportion of induction, forceps delivery, and total labour complications was significantly lower than in the multiparous group ${ }^{[8]}$.

Al-sibai et al, reviewed 1130 patients who had 7 or more viable pregnancies at the University Teaching Hospital in Al-Khobar, Saudi Arabia. Delivery complications were higher for the study group, however, than for total deliveries: breech deliveries, $7 \%$ vs. $2.7 \%$; premature labour, $7.5 \%$ vs. 2.7 ; caesarean section, $11.4 \%$ vs. $8.9 \%$; and postpartum haemorrhage. $6.5 \%$ vs. $3.1 \%{ }^{[14]}$.

Rizk DE et al, reviewed the records of 418 grand multiparous women (study group), defined as having had given birth at least 5 times after completed 22 weeks gestational age, and 418 women of parity 2-4 (control group). Diabetes mellitus (both overt and gestational) was significantly more common in the study group) but there was no significant increase in the incidence of other- obstetric complications or in perinatal mortality rate. Babies of grand multiparous mothers required significantly more admissions to special care unit because of maternal diabetes mellitus ${ }^{[16]}$.

Sipila P. et al found that the grand multipara had a higher incidence of essential hypertension than women of lower parity. The grand multipara had fewer caesarean sections ( $7.5 \%$ vs. $14.1 \%)$ and vacuum extractions $(0.5 \%$ vs. $5.1 \%$ o but more inductions of labour $(33.1 \%$ vs. $23.5 \%)$ than mothers of lower parity ${ }^{[19]}$.

Karl Fuchs et al study is based on 5785 cases of GM which were compared to the general obstetrical population in terms of pregnancy and delivery complications. Face and breech presentations as well as transverse lie were twice, brow presentations were three times as frequent in the GM group. Postpartum haemorrhage (P.P.H.) was four times and premature separation of the placenta twice as frequent. Rupture of the uterus was about 20 times more frequent. Forceps delivery and caesarean section rate were twice, while the vacuum extraction 5 -fold more frequent. Though there was no maternal mortality, and perinatal mortality was not higher than in the general population. ${ }^{[22]}$.

A total of 7785 mothers was studied, $889(11.5 \%)$ by Eideiman of whom were grandmultiparas. Comparison of grandmuftiparous mothers with all others revealed no increase in the incidence of hypertension, diabetes, uterine atonia, antenatal or postnatal haemorrhage, caesarean sections, stillbirth rate, or congenital malformations. The grandmultipara had significantly lower neonatal mortality and low birth weight rates and a significantly higher incidence of multiple births and trisomy $21^{[30]}$.

A retrospective analysis of 646 Arab grandmultiparas who booked for hospital confinement between 1983 and 1985 was carried out. The results were compared with that of non-grandmultiparas during the same period. In the grandmultiparas, the incidences of gestational diabetes, hypertension, rheumatic heart disease, antepartum, postpartum haemorrhage and macrosomic infants were increased. However, contrary to some previous reports the incidences of anemia, caesarean sections, induced labour, dysmaturity and perinatal deaths 
were decreased. This is thought to be due to the provision of modern specialist perinatal care and improved socioeconomic standards ${ }^{[31]}$.

\subsubsection{Maternal Mortality rate (MMR)}

Every minute of every day some where in the world, a woman dies as a result of complications arising during pregnancy and childbirth the majority of these deaths are avoidable. Maternal death is a tragedy for individual women, for families, and for their communities The medical causes of maternal deaths are similar throughout the world.

Maternal mortality is the death of a women while pregnant or within 42 days of termination of pregnancy, regardless of the site or duration of pregnancy, from any cause related to or aggravated by pregnancy or its mismanagement direct or indirect [WHO].

A report of the special obstetric characteristics of grand multiparas (GMPs) and the extent to which the parturient age affect the incidence of complications was done in a series of 1567 deliveries over 10 years in the same hospital in Oulu, Finland, differences were noted between the obstetric behaviour of GMPs as compared with other parturients, the maternal mortality rate of GMPs in the series was significantly higher than that of the other parturient (12\%). The primary causes of death were abruptio placentae, rupture of the uterus and eclampsia a state of shock was a feature common to all the fatalities ${ }^{[12]}$.

Ogedengbe OK, found that The maternal mortality ratio was 44.4/1000 amongst the grandmultipara which was not statistically more significant than in the general obstetric population ${ }^{[10]}$.

2.3 Fetal Outcome

G. J. Bugg et al found that there was one stillbirth and two neonatal deaths in the grandmultiparous group and two stillbirths and three neonatal deaths in the multiparous group. Mean birth weights were $3329 \mathrm{~g}(720)$ in the grandmultiparous group and $3307 \mathrm{~g}(695)$ in the multiparous group. No significant differences in neonatal outcomes were found between the two groups ${ }^{[9]}$.

Hecht-Resnick et al, found that Macrosomia was markedly higher in the grandmultiparas and multiparas than in nulliparas ${ }^{[11]}$.

A Babinski, T Kerenyi found that low apgar scores and macrosomia, were significantly higher in grand multiparas than in multiparas although perinatal mortality remains low in these patients ${ }^{[8]}$.

From 1971 to 1988, out of 22001 deliveries (multiple pregnancies excluded) Newborn infants in the GMPs group were severely asphyxiated at birth more frequently than those in the control group. The overall perinatal death rate in the GMPs and control group was $2.83 \%$ and $1.81 \%$, respectively $y^{[36]}$.

A total of 382 grand multiparous women (para $>$ or $=5$ ) were compared with 382 age-matched control subjects (para 2 to 4), all delivering between July 1989 and September 1991, Grand multiparity was associated with an increased incidence of macrosomia $(16 \%$ vs $11 \%)$, Macrosomia increased the incidence of intrapartum complications from $31 \%$ to $46 \%(\mathrm{p}<0.03)$ in the grand multiparous patients, and a trend was observed in the multiparous patients, from $26 \%$ to $37 \%$. However, when properly controlled, this was noted to be a confounding variable and was not related to parity ${ }^{[7]}$.

\section{Justification of the study}

The Grand Multipara (GMP) has almost disappeared in the western countries (3-4\% of all birth)[36]. due to the improvement of economic status, advancement of family planning and elective termination of pregnancy, In our country Sudan- having heterogeneous population- the problem of grandmultiparity still exsit. For that reason and because we have a good improvement in the setup of our medical services in the last few years, we focus on a relevant clinical questions:

Grand Multiparous woman in our population, is she at increased risk of complications? and multiparous lady, is she really in the safe group, called safe parity?

\subsection{General:}

\section{Objectives}

To compare the incidence of maternal and fetal complications of pregnancy and labor between grandmultiparae and multiparous women.

4.2 Specific:

4.2.1 Maternal:

To compare the two groups in the incidence of

1 -antepartum complications (hypertension, diabetes mellitus and anaemia).

2-Intrapartum complications (multiple, pregnancy, presentation, and APH).

3 -Post partum complications (mode of delivery, $\mathrm{PPH}$, and maternal mortality).

4.2.2 Fetal: 
to compare the incidence of respiratory distress, admission to the nursery, fetal weight, and stillbirth between two groups.

\subsection{Study design:}

\section{Methodology}

This is a prospective case control, hospital based study.

\subsection{Study area:}

This study was done in Omdurman Maternity Hospital(OMH), and Khartoum North Teaching Hospital(KNTH), they are two major hospital in Khartoum, the capital of Sudan (population more than 5.2 millions).[38].

Omdurman Maternity Hospital(OMH), is the first specialized hospital in Sudan that has been established in 1957. The hospital cover the area of Omdurman, (population about 2.3 millions), receives patients from different areas of Khartoum, and some patients come from other parts of Sudan, the hospital contains labor wards, antenatal wards, and postnatal wards. there is a blood bank laboratory, two theatres (elective and emergency).department of laparoscopic surgery, well equipped neonatal unit (SCBU). Pharmacy, ICU. The labour ward contains 25 beds, ultrasound and CTG. machines The total number of beds are 136, the services are covered by consultants ,registrars, house officers, sisters and midwifes, distributed in five units, the average number of deliveries are about 70 to 100 per day.

Khartoum North Teaching hospital (KNTH) is central hospital that provides services to most of the inhabitants of Khartoum north and east Nile, population about (1450000), KNTH services cover the relevant branches of medicine, surgery, pediatrics, pediatrics surgery, dermatology, orthopedics, E.N.T, Obstetrics and Gynaecology, blood bank, laboratory, pharmacy, Services in the obstetrics and Gynaecology unit are covered by consultants, registrars, house officers and midwives divided into five units. The department is separated and composed of labor room, theatre, neonatal unit, antenatal wards postnatal wards, septic and gynecology wards and eclampsia room, there are US and CTG unit in the hospital, the average number of deliveries are about 40 to 50 per day. In the two hospital about $15 \%$ GMP and $60 \%$ multiparous woman.

\subsection{Study population:}

All pregnant women who delivered in Omdurman maternity and Khartoum North Teaching Hospitals who had been fulfilling the inclusion criteria in the period of the study.

\subsection{Inclusion criteria:}

A case is defined as a woman who delivered 5 or more after 24 weeks gestation (group A).

Control is defined as woman who delivered 1 to 4 birth after 24 weeks gestation (group B).

Willingness to participate in the study.

Exclusion criteria:

primigravidas.

Women with previous caesarian section.

Refusal to participate in the study.

\subsection{Data collection:}

a detailed questionnaire, was designed, and filled by direct questioning, examination and follow up of the patients since admission till discharge from hospital, I observed and followed up the patients during their stay in the hospital and filled the questionnaire in a proper way, and, I trained some doctors who were working in the labour room about how to fill the questionnaire correctly because they did that during my rest time and when there were more than one patient laboring at the same time.

During our data collection we did not interfere with the hospital protocol of management of patients.

The questionnaire consists of:

o Personal history

o Parity.

o Social class which was classified to low, moderate or high. According

family income.

o gestational age in weeks and days

o haemoglobin measurement .

o Urine analysis was done for Albumin.

o diabetes mellitus ,hypertentions, and a anemia.

o Duration of the first Stage: the time from active labor until the cervix becomes fully dilated( 2 to 6 hour) [29] 
o Number of fetuses: singletone twins, triplet.

o presentation: cephalic, breech, others.

o Indication of Em c/s.

o Complications during pregnancy .

o Intrapartum complications.

o Causes of PPH.

o Fetal outcome: alive, stillbirth.

o apgar score.

o Birth weight:

Data Analysis:

Data was entered into SPSS (statistical package for social science) computerized program for analysis, chisquare and $\mathrm{P}$ value less than 0.05 was considered significant.

Data Presented in tables and graphs.

Ethics:

1-informed consent was taken verbally from patient and we stress the fact that participation of this study was voluntary.

2- Approval to do this study was taken from the general director of Omdurman Maternity Hospital.

\section{Results}

A total of 450 patients, 150 were cases (GMPs) and 300 were control group Multiparas (Para1-4) were studied. Data was collected and analyzed using statistical package of social science SPSS17.

The results of the study were presented in tables \& figures.

Table (1):

Shows the distribution of the cases and control groups by their ages $0.7 \%$ of the cases were less than 20 years old, compared to $3.7 \%$ of the control group.

On the other hand $38.0 \%$ of the cases were above 35 years old, while only $9.0 \%$ of the control group.

This difference is statistically highly significant. $(\mathrm{P}=0.00)$.

Figure(1):

Shows the correlation between the parity and socioeconomic status. $48.0 \%$ of the cases were found to be of low socioeconomic status compared with $28.7 \%$ of the control group.

$42.7 \%$ of the cases were found to be of moderate socioeconomic status compared with $46.3 \%$ of control group.

$9.3 \%$ of the cases were found to be of high socioeconomic status compared with $25 \%$ of the control group.

This difference is statistically significant. $\mathrm{P}<0.05$.

Figure (2):

Shows the relation between parity, and gestational ages of the two groups.

$16.0 \%$ of cases had gestation ages less than 37 weeks (preterm labour), while $12.7 \%$ the control group had.

$62.7 \%$ of cases had gestation ages 37 to 40 weeks (term), while $60.3 \%$ the control group had.

$21.3 \%$ of cases had gestation ages more than 40 weeks (post-term), while $27,0 \%$ the control group had.

This difference is statistically not significant. $\mathrm{P}>0.05$.

Figure (3):

Shows the correlation between parity and hypertensive disorders of pregnancy.

Of the grandmultipara $30.0 \%$ had hypertension disorders of pregnancy while $13.7 \%$ of the multipara had.

This difference is statistically significant. $\mathrm{P}<0.05$.

Figure (4):

Shows the distribution of cases and control group by presence of DM or gestational DM.

$8.0 \%$ of the cases were found to have the disorder while, $3.0 \%$ of the control group had.

This difference is statistically significant. $\mathrm{P}>0.05$.

Figure (5):

Shows the distribution of cases and control group by the presence of anaemia or not.

$28.7 \%$ of the grandmultipra had anaemia while $12.7 \%$ of the control group had.

The difference is statistically significant. $\mathrm{P}<0.05$.

Figure (6):

Shows the relation between parity and multiple pregnancy. $8.0 \%$ of cases had multiple pregnancy while $3.3 \%$ of control group had.

This difference is statistically significant. $\mathrm{P}<0.05$

Figure (7):

Shows the correlation between parity and presentation. 
$9.4 \%$ of the grand multipra had breech presentation while $5.5 \%$ of the control group had.

$3.6 \%$ of cases had transverse lie compared to $0.3 \%$ of the control group had.

This difference is statistically significant. $\mathrm{P}<0.05$.

Table(2):

Shows transverse lie, and face presentation.

In transverse lie there were $80 \%$ in cases and $20 \%$ in the controls group.

In face presentation all the cases were in control group .

This difference is statistically not significant. $\mathrm{P}>0.05$.

Figure (8):

Shows the distribution of the cases and control group according to antipartum hemorrhage (APH).

$2.7 \%$ of the cases had bleeding due to placenta previa while $4.0 \%$ of the control had.

$6.0 \%$ of the grand multipara had bleeding due to abruptio placentae compared to $1.7 \%$ of the multipara

This difference is statistically significant. $\mathrm{P}<0.05$.

Table(3):

Shows the relation between parity and onset of labour. $2.0 \%$ of the GMPs had induction of labour, while $11.0 \%$ of the Multipara had.

This difference is statistically highly significant. $(\mathrm{P}=001)$.

Table (4):

Shows the relation between parity and the duration of the first stage of labour.18.0\% of GMP had first stage of labour less than 2 hours while $7.7 \%$ control had.

$21.3 \%$ of GMP had first stage of labour more than 6 hours while $47.7 \%$ control had.

This difference is statistically highly significant. $(\mathrm{P}=0.00)$.

Figure (9):

Shows the distribution of cases and control groups by the mode of delivery.

$76.7 \%$ of cases had SVD compared with $60.3 \%$ in control group.

Assisted VD was $6.0 \%$ in cases compared with $12.0 \%$ in control group.

Ems $\mathrm{C} / \mathrm{S}$ was $17.3 \%$ in cases compared to $27.7 \%$ of control group.

This difference is statistically significant. $\mathrm{P}<0.05$.

Table (5):

Compare the indications of emergency caesarean sections in the two groups.

Failure to progress: $9.1 \%$ in GMPs while $90.9 \%$ were in the control group.

Fetal distress: $27.3 \%$ in GMPs while $72.7 \%$ were in the control group.

Obstructed labour: $14.3 \%$ in GMPs while $85.7 \%$ were in the control group.

Abnormal lie: $83.3 \%$ in GMPs while $16.7 \%$ were in the control group.

APH: $32.0 \%$ in GMPs while $68.0 \%$ were in the control group.

PE: $16.7 \%$ in GMPs while $83.3 \%$ were in the control group.

Others causes: $40.0 \%$ in GMPs while $60.0 \%$ were in the control group.

This difference is statistically significant $\mathrm{P}=003$.

Figure (11):

Shows the distribution of the cases and control group by presence of $\mathrm{PPH}$.

$8.7 \%$ of cases had PPH compared to

$9.7 \%$ of control group.

This difference is statistically not significant. $\mathrm{P}>0.05$.

Table (6):

Compare the causes of PPH in the two groups.

Uterine atony: $75.0 \%$ in GMPs, while $25.0 \%$ in the control group.

Genital tract injury : $19.0 \%$ in GMPs, while $81.0 \%$ in the control group.

Retained products : $14.3 \%$ in GMPs, while $85.7 \%$ in the control group.

Blood coagulpathy : $33.3 \%$ in GMPs, while $66.7 \%$ in the control group.

This difference is statistically significant. $\mathrm{P}<0.05$.

Table (7):

Shows the types of genital tract injuries in the two groups.

Ruptured uterus : $20.0 \%$ in the GMPs, while $80.0 \%$ in the control group. $25.0 \%$ of perineal tear: $10.0 \%$ in the GMPs, while $90.0 \%$ in the control group.

Extended episiotomy: $25.0 \%$ in the GMPs, while $75.0 \%$ in the control group.

Other causes: $50.0 \%$ in the GMPs, while $50.0 \%$ in the control group.

This difference is statistically not significant. $\mathrm{P}>0.05$.

Figure (12): 
Shows the relation between parity and maternal death.

$0.7 \%$ (1-woman) of the cases died compared to $1.0 \%$ ( 3 women) died from the control group.

This difference is statistically not significant.P $>0.05$.

Table (8):

Shows the causes of maternal death between the two groups:

PPH: $33.3 \%$ in GMPs, while $66.7 \%$ in the control group.

pulmonary embolism : all the cases were in the control group.

This difference is statistically not significant. $\mathrm{P}>0.05$.

Figure (13):

Shows the relation between parity and fetal outcome.

$89.9 \%$ of the GMPs had alive babies, while $90.0 \%$ of the control had.

$10.1 \%$ of the GMPs had still birth babies, while $10.0 \%$ of the control had.

This difference is statistically not significant. $\mathrm{P}>0.05$.

Table (8):

Shows the babies's apgar score in the two groups.

$1.6 \%$ of the GMP babies had apgar score 4 to 6 while multiparas had $3.4 \%$.

$1.6 \%$ of the GMP babies had apgar score less than 3, while multiparas had $0.8 \%$.

This difference is statistically not significant. $\mathrm{P}>0.05$.

Table (9):

Compare the condition of the babies after birth between two groups

$3.2 \%$ of the babies of the GMP were distressed, while $4.2 \%$ of the multiparas's babies were.

This difference is statistically not significant. $\mathrm{P}>0.05$.

Table (11):

Shows the fate of the distressed babies after delivery in the two groups.

resuscitated and beside their mothers: $12.5 \%$ in the GMP, while $87.5 \%$ were in the control group. admitted to SCBU: $42.9 \%$ in the GMP, while $57.1 \%$ were in the control group.

This difference is statistically not significant. $\mathrm{P}>0.05$.

Table (12):

Compare the fresh and macerated still birth between two groups.

Fresh still birth: $25.0 \%$ were babies of GMP, while $75.0 \%$ of control group.

macerated still birth: $40.9 \%$ were babies of GMP, while $59.1 \%$ of control group.

This difference is statistically not significant. $\mathrm{P}>0.05$.

Figure (15):

Shows the relation between parity and birth weight

$7.2 \%$ of cases delivered baby weight less than 2500 gm compared to $11.0 \%$ of control group.

$73.9 \%$ of cases delivered babies with weight between $2500 \mathrm{gms}$ and $4000 \mathrm{gms}$, compared to $83.1 \%$ of control group.

$18.8 \%$ of cases delivered babies with weight more than $4000 \mathrm{gm}$, compared to $5.9 \%$ of control group.

This difference is statistically significant. $\mathrm{P}<0.05$

Table (1):Showing the distribution of the cases and control groups by their ages

\begin{tabular}{|c|c|c|c|c|c|c|}
\hline & & & Age gr & & & \\
\hline & & & $<20$ & $20-35$ & $>35$ & Total \\
\hline Study population & Cases & Count & 1 & 92 & 57 & 150 \\
\hline & & $\%$ & $.7 \%$ & $61.3 \%$ & $38.0 \%$ & $100.0 \%$ \\
\hline & Controls & Count & 11 & 262 & 27 & 300 \\
\hline & & $\%$ & $3.7 \%$ & $87.3 \%$ & $9.0 \%$ & $100.0 \%$ \\
\hline & Total & Count & 12 & 354 & 84 & 450 \\
\hline & & $\%$ & $2.7 \%$ & $78.7 \%$ & $18.7 \%$ & $100.0 \%$ \\
\hline
\end{tabular}




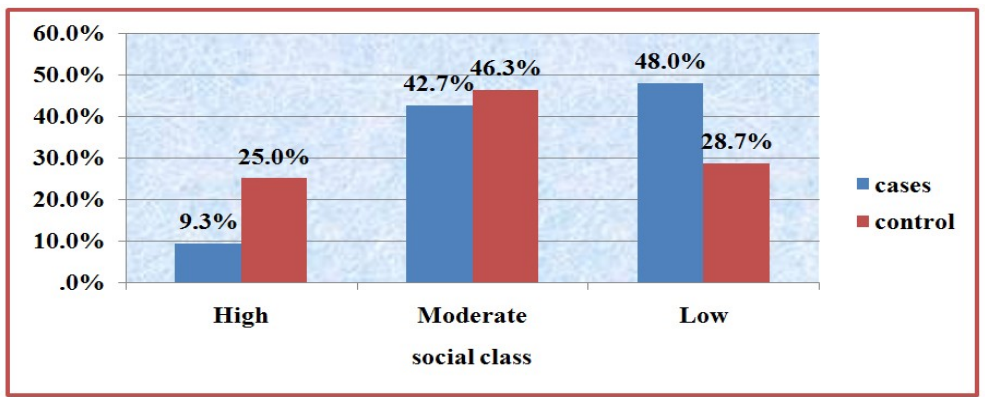

Fig (1) showing distribution according to socioeconomic class

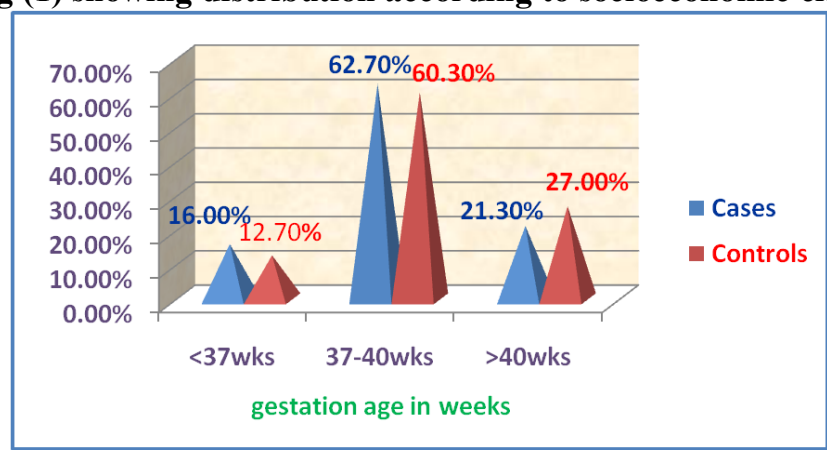

Fig (2) showing the relation between parity and gestational age

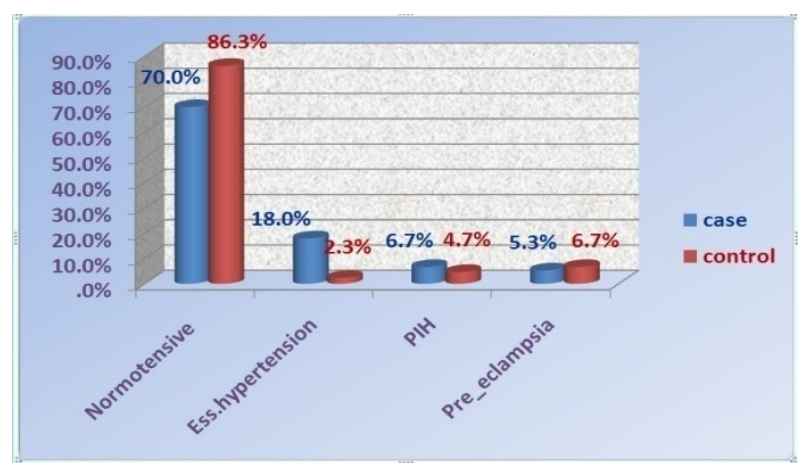

Figure(3) Showing the correlation between parity and hypertensive disorders of pregnancy.

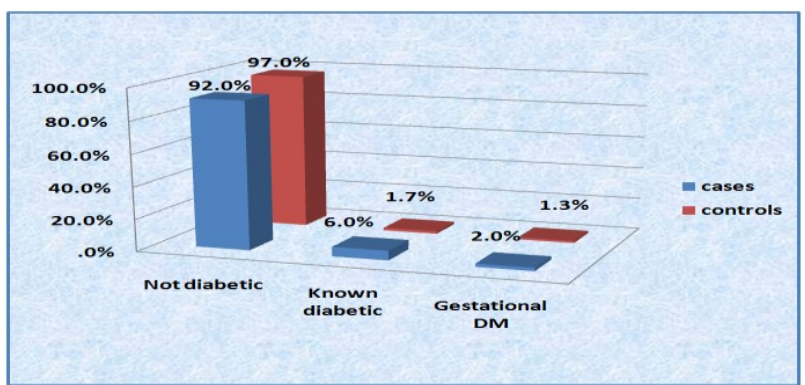

Figure(4) Showing the distribution of cases and control by presence of DM or gestational DM.

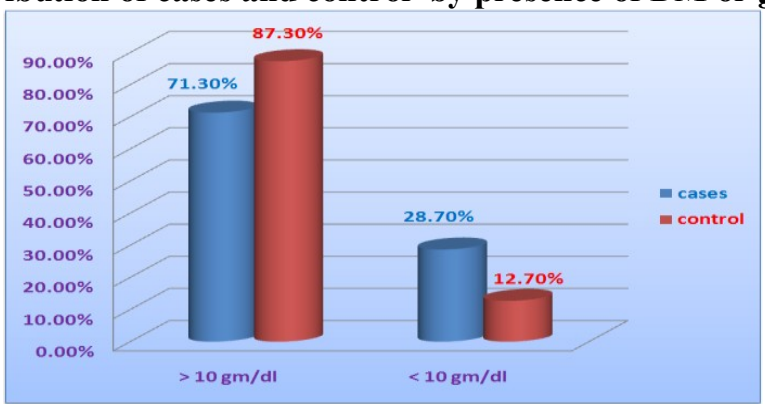

Figure(5) Showing the distribution of cases and control by the presence of anaemia or not. 


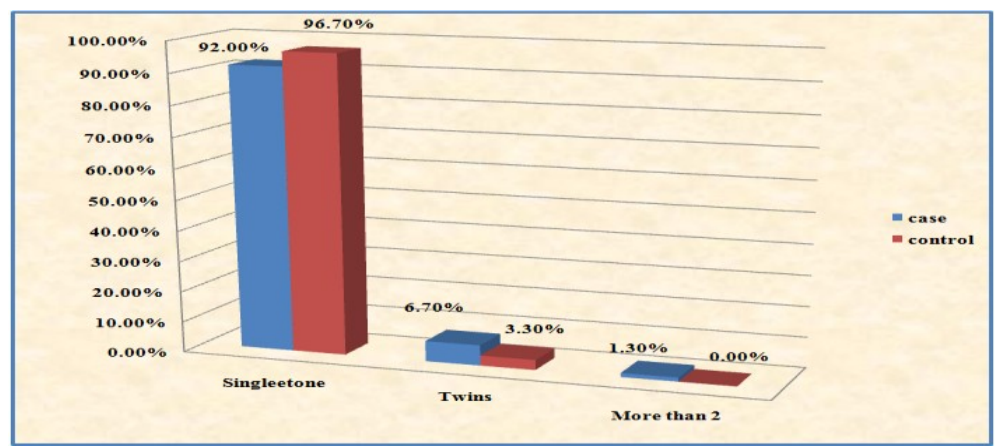

Figure (6): Shows the relation between parity and multiple pregnancy.

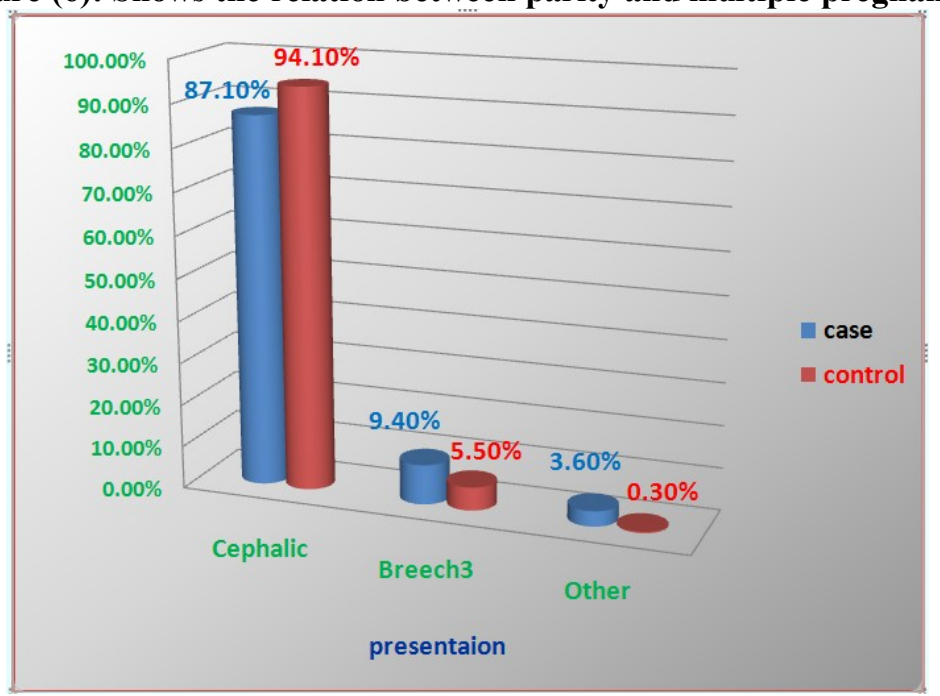

Figure (7) Showing the correlation between parity and presentation.

Table(2): showing transverse lie and face presentation

\begin{tabular}{|l|l|l|l|l|}
\hline \multicolumn{2}{|c|}{} & Cases & Controls & Total \\
\hline \multirow{2}{*}{ Transvese lie } & Count & 4 & 1 & 5 \\
\cline { 2 - 6 } & $\%$ & $80.0 \%$ & $20.0 \%$ & $100.0 \%$ \\
\hline \multirow{2}{*}{ face } & Count & 1 & 0 & 1 \\
\cline { 2 - 6 } & $\%$ & $100.0 \%$ & $.0 \%$ & $100.0 \%$ \\
\hline \multirow{2}{*}{ Total } & Count & 5 & 1 & 6 \\
\cline { 2 - 6 } & $\%$ & $83.3 \%$ & $16.7 \%$ & $100.0 \%$ \\
\hline
\end{tabular}

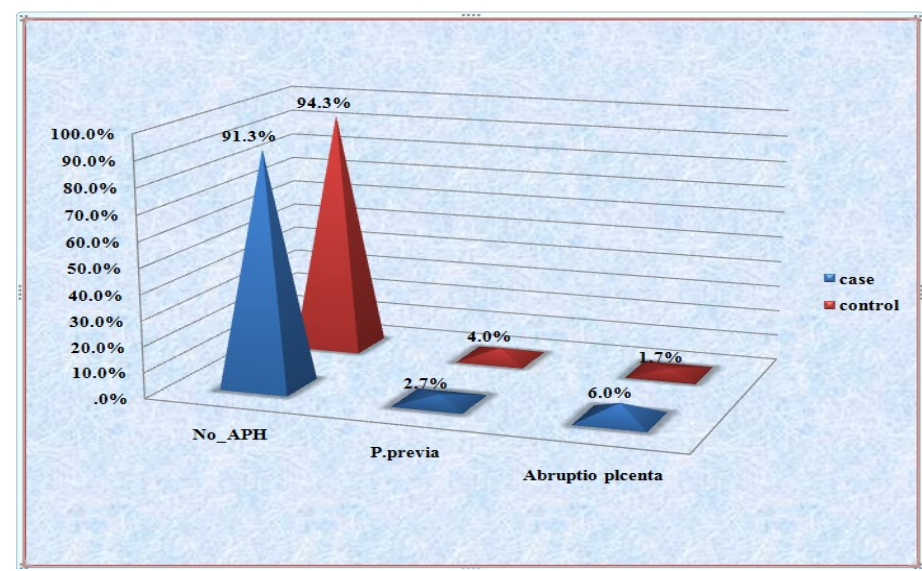

Figure (8) Shows the distribution of the cases and control group according to antipartum hemorrhage (APH). 
Table(3): Showing the relation between parity and onset of labour

\begin{tabular}{|c|c|c|c|c|c|}
\hline & & & \multicolumn{3}{|c|}{ Onest_of_labor } \\
\hline & & & Spontaneous & Induced & Total \\
\hline \multirow[t]{6}{*}{ Study population } & \multirow[t]{2}{*}{ Cases } & Count & 147 & 3 & 150 \\
\hline & & $\%$ & $98.0 \%$ & $2.0 \%$ & $100.0 \%$ \\
\hline & \multirow[t]{2}{*}{ Controls } & Count & 267 & 33 & 300 \\
\hline & & $\%$ & $89.0 \%$ & $11.0 \%$ & $100.0 \%$ \\
\hline & \multirow[t]{2}{*}{ Total } & Count & 414 & 36 & 450 \\
\hline & & $\%$ & $92.0 \%$ & $8.0 \%$ & $100.0 \%$ \\
\hline
\end{tabular}

Table(4) showing the duration of the first stage of labour

\begin{tabular}{|l|l|l|l|l|l|l|}
\hline & & \multicolumn{5}{|c|}{ Duration_of_first_stage } \\
\hline & & & $<2$ hours & $2-6$ hours & $>6$ hours & Total \\
\hline \multirow{3}{*}{ Study population } & \multirow{2}{*}{ Cases } & Count & 27 & 91 & 32 & 150 \\
\cline { 3 - 8 } & & $\%$ & $18.0 \%$ & $60.7 \%$ & $21.3 \%$ & $100.0 \%$ \\
\cline { 2 - 7 } & \multirow{2}{*}{ Controls } & Count & 23 & 134 & 143 & 300 \\
\cline { 3 - 7 } & & $\%$ & $7.7 \%$ & $44.7 \%$ & $47.7 \%$ & $100.0 \%$ \\
\hline & \multirow{2}{*}{ Total } & Count & 50 & 225 & 175 & 450 \\
\hline & & $\%$ & $11.1 \%$ & $50.0 \%$ & $38.9 \%$ & $100.0 \%$ \\
\hline
\end{tabular}

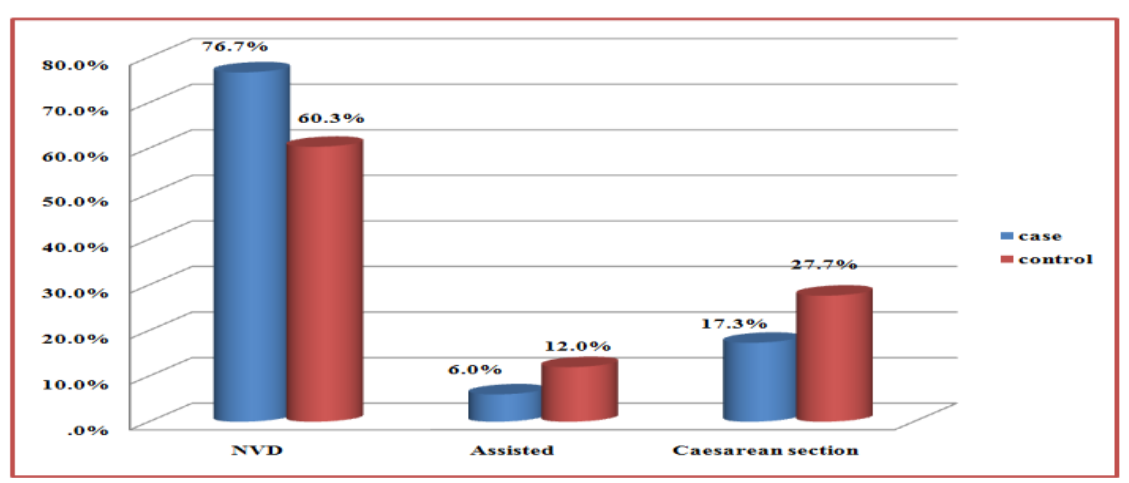

Figure (9) Showing the distribution of cases and control groups by the mode of delivery.

Table (5): compare the the indications of emergency ClS in the two groups

\begin{tabular}{|c|c|c|c|c|}
\hline & & Cases & Controls & Total \\
\hline \multirow[t]{2}{*}{ Failure to progress } & Count & 4 & 40 & 44 \\
\hline & $\%$ & $9.1 \%$ & $90.9 \%$ & $100.0 \%$ \\
\hline \multirow[t]{2}{*}{ Fetal distress } & Count & 3 & 8 & 11 \\
\hline & $\%$ & $27.3 \%$ & $72.7 \%$ & $100.0 \%$ \\
\hline \multirow[t]{2}{*}{ Obstructed labour } & Count & 1 & 6 & 7 \\
\hline & $\%$ & $14.3 \%$ & $85.7 \%$ & $100.0 \%$ \\
\hline \multirow[t]{2}{*}{ Abnormal lie } & Count & 5 & 1 & 6 \\
\hline & $\%$ & $83.3 \%$ & $16.7 \%$ & $100.0 \%$ \\
\hline \multirow[t]{2}{*}{ APH } & Count & 8 & 17 & 25 \\
\hline & $\%$ & $32.0 \%$ & $68.0 \%$ & $100.0 \%$ \\
\hline \multirow[t]{2}{*}{$\mathrm{PE}$} & Count & 1 & 5 & 6 \\
\hline & $\%$ & $16.7 \%$ & $83.3 \%$ & $100.0 \%$ \\
\hline \multirow[t]{2}{*}{ 0thers } & Count & 4 & 6 & 10 \\
\hline & $\%$ & $40.0 \%$ & $60.0 \%$ & $100.0 \%$ \\
\hline Total & Count & 26 & 83 & 109 \\
\hline
\end{tabular}


Maternal and Fetal Outcome of Grandmultipara in Comparison to Multiparous Woman in Two

\begin{tabular}{|c|c|c|c|c|}
\hline & & Cases & Controls & Total \\
\hline \multirow[t]{2}{*}{ Failure to progress } & Count & 4 & 40 & 44 \\
\hline & $\%$ & $9.1 \%$ & $90.9 \%$ & $100.0 \%$ \\
\hline \multirow[t]{2}{*}{ Fetal distress } & Count & 3 & 8 & 11 \\
\hline & $\%$ & $27.3 \%$ & $72.7 \%$ & $100.0 \%$ \\
\hline \multirow[t]{2}{*}{ Obstructed labour } & Count & 1 & 6 & 7 \\
\hline & $\%$ & $14.3 \%$ & $85.7 \%$ & $100.0 \%$ \\
\hline \multirow[t]{2}{*}{ Abnormal lie } & Count & 5 & 1 & 6 \\
\hline & $\%$ & $83.3 \%$ & $16.7 \%$ & $100.0 \%$ \\
\hline \multirow[t]{2}{*}{ APH } & Count & 8 & 17 & 25 \\
\hline & $\%$ & $32.0 \%$ & $68.0 \%$ & $100.0 \%$ \\
\hline \multirow[t]{2}{*}{ PE } & Count & 1 & 5 & 6 \\
\hline & $\%$ & $16.7 \%$ & $83.3 \%$ & $100.0 \%$ \\
\hline \multirow[t]{2}{*}{ 0thers } & Count & 4 & 6 & 10 \\
\hline & $\%$ & $40.0 \%$ & $60.0 \%$ & $100.0 \%$ \\
\hline \multirow[t]{2}{*}{ Total } & Count & 26 & 83 & 109 \\
\hline & $\%$ & $23.9 \%$ & $76.1 \%$ & $100.0 \%$ \\
\hline
\end{tabular}

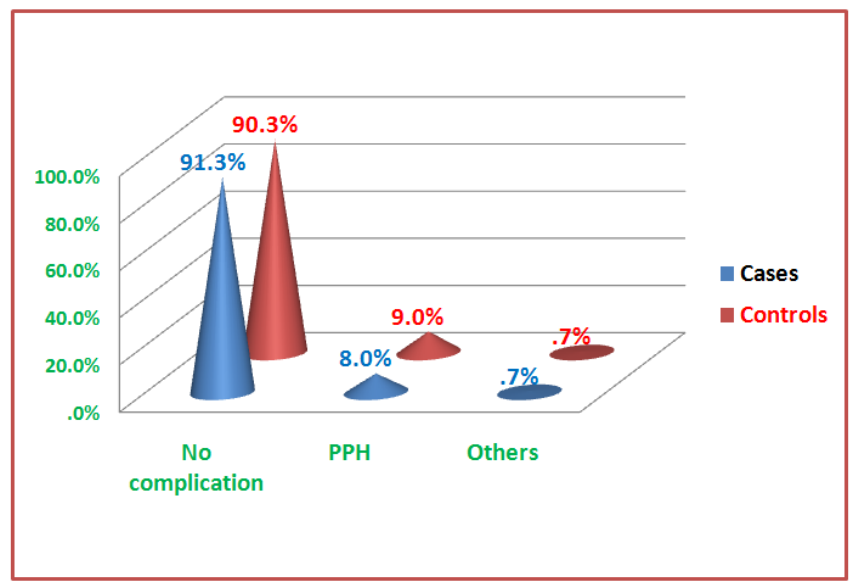

Figure (10) Showing the distribution of the cases and control group by presence of PPH.

Table(6): Compare the causes of PPH in the two groups

\begin{tabular}{|l|l|l|l|l|}
\hline \multicolumn{2}{|l}{} & Cases & Controls & Total \\
\hline \multirow{4}{*}{ Uterine atony } & Count & 6 & 2 & 8 \\
\hline \multirow{3}{*}{ Gentital tract injury } & $\%$ & $75.0 \%$ & $25.0 \%$ & $100.0 \%$ \\
\hline \multirow{3}{*}{ Retained product } & Count & 4 & 17 & 21 \\
\hline \multirow{3}{*}{ Blood coagulpathy } & $\%$ & $19.0 \%$ & $81.0 \%$ & $100.0 \%$ \\
\hline \multirow{5}{*}{ Total } & Count & 1 & 6 & 7 \\
\cline { 2 - 6 } & $\%$ & $14.3 \%$ & $85.7 \%$ & $100.0 \%$ \\
\hline & Count & 1 & 2 & 3 \\
\hline & $\%$ & $33.3 \%$ & $66.7 \%$ & $100.0 \%$ \\
\hline & Count & 12 & 27 & 39 \\
\hline
\end{tabular}


Table(7): showing types of genital tracts injuries

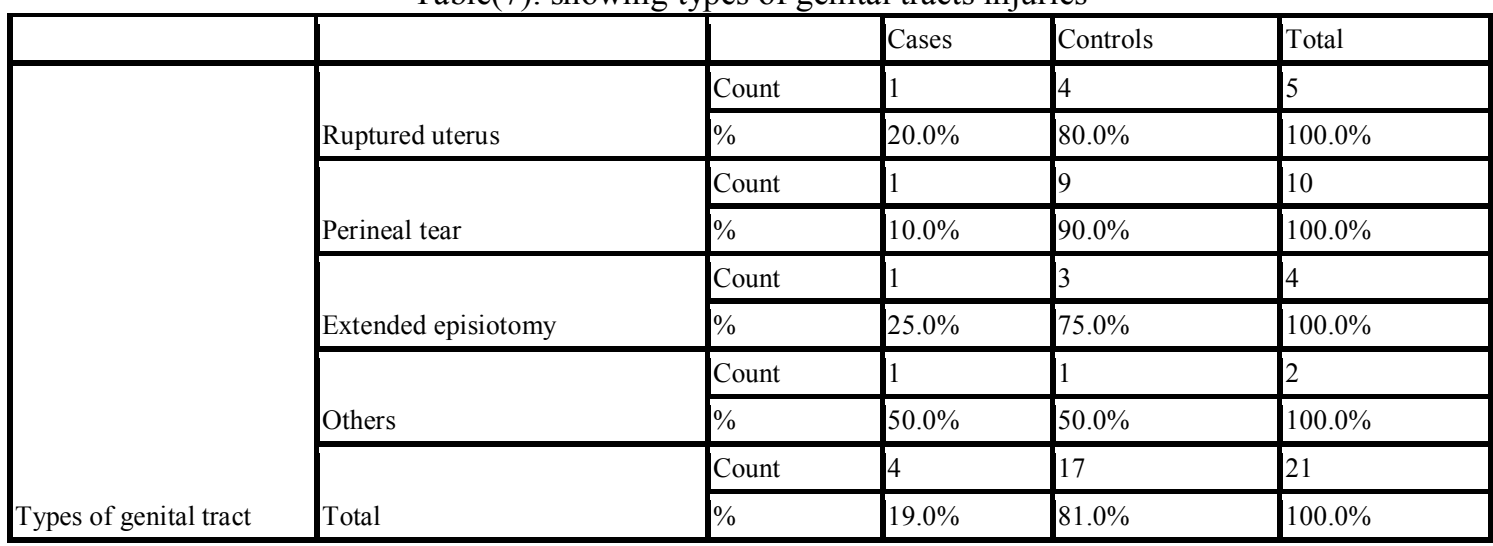

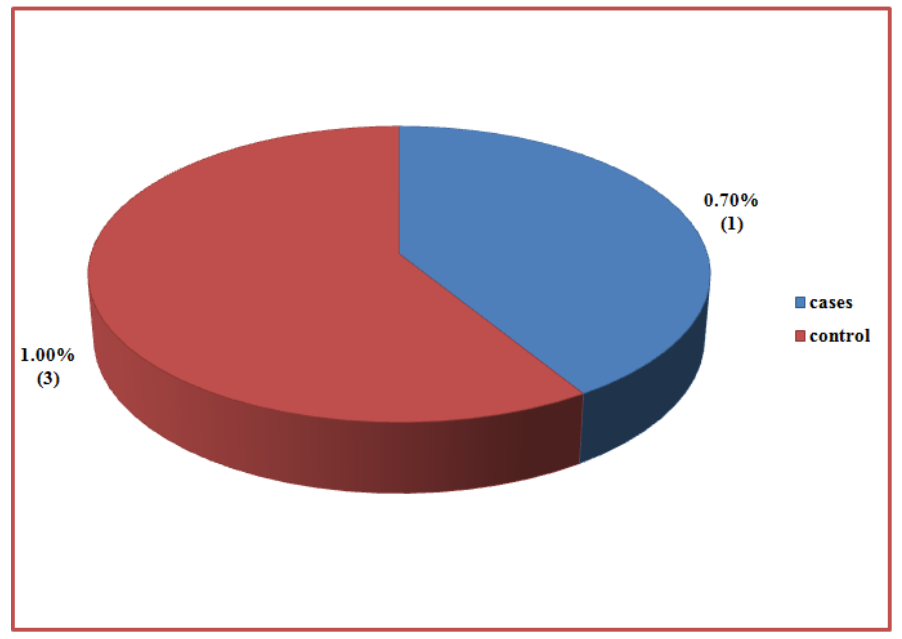

Figure(11) Showing the relation between parity and maternal death.

Table(8) showing the causes of maternal death

\begin{tabular}{|c|c|c|c|c|c|}
\hline & & & Cases & Controls & Total \\
\hline \multirow[b]{4}{*}{ Causes of maternal deaths } & \multirow{2}{*}{$\mathrm{PPH}$} & Count & 1 & 2 & 3 \\
\hline & & $\%$ & $33.3 \%$ & $66.7 \%$ & $100.0 \%$ \\
\hline & \multirow[b]{2}{*}{ P- embolism } & Count & 0 & 1 & 1 \\
\hline & & $\%$ & $.0 \%$ & $100.0 \%$ & $100.0 \%$ \\
\hline & \multirow[b]{2}{*}{ Total } & Count & 1 & 3 & 4 \\
\hline & & $\%$ & $25.0 \%$ & $75.0 \%$ & $100.0 \%$ \\
\hline
\end{tabular}




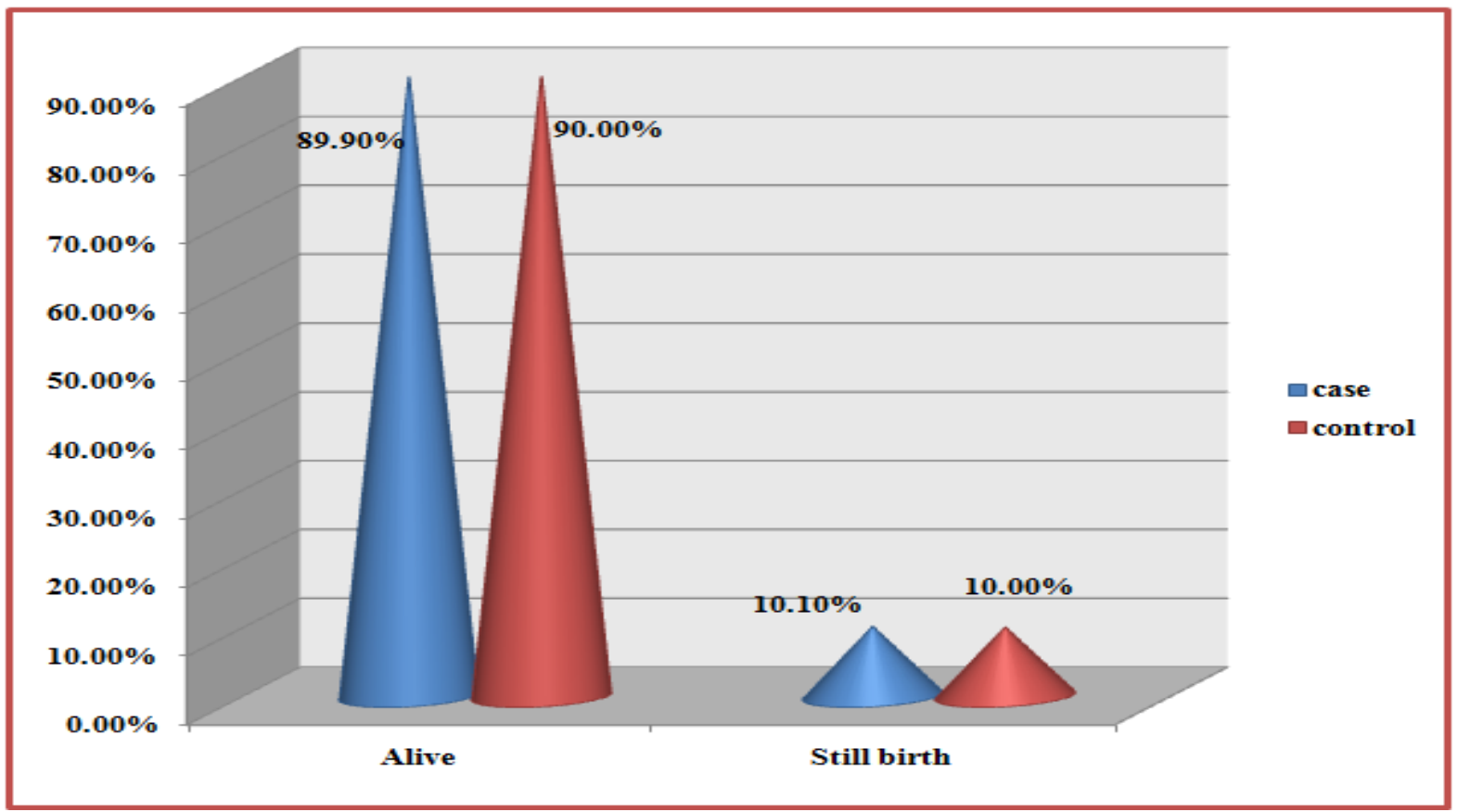

Figure (12) Showing the relation between parity and fetal outcome.

Table (9) Showing the babies' apgar score in the two groups

\begin{tabular}{|c|c|c|c|c|c|c|}
\hline & & & \multicolumn{4}{|c|}{ Apgar score } \\
\hline & & & $>=7$ & 4 to 6 & $k=3$ & Total \\
\hline \multirow[b]{4}{*}{ Study population } & \multirow[b]{2}{*}{ Cases } & Count & 120 & 2 & 2 & 124 \\
\hline & & $\%$ & $96.8 \%$ & $1.6 \%$ & $1.6 \%$ & $100.0 \%$ \\
\hline & \multirow[b]{2}{*}{ Controls } & Count & 250 & 9 & 2 & 261 \\
\hline & & $\%$ & $95.8 \%$ & $3.4 \%$ & $.8 \%$ & $100.0 \%$ \\
\hline & \multirow[b]{2}{*}{ Total } & Count & 370 & 11 & 4 & 385 \\
\hline & & $\%$ & $96.1 \%$ & $2.9 \%$ & $1.0 \%$ & $100.0 \%$ \\
\hline
\end{tabular}

Table(10) Compare the condition of the babies after birth between two groups

\begin{tabular}{|c|c|c|c|c|c|}
\hline & & & Not distressed & Baby distressed & Total \\
\hline \multirow[b]{4}{*}{ Study population } & \multirow[b]{2}{*}{ Cases } & Count & 120 & 4 & 124 \\
\hline & & $\%$ & $96.8 \%$ & $3.2 \%$ & $100.0 \%$ \\
\hline & \multirow[b]{2}{*}{ Controls } & Count & 250 & 11 & 261 \\
\hline & & $\%$ & $95.8 \%$ & $4.2 \%$ & $100.0 \%$ \\
\hline & \multirow[b]{2}{*}{ Total } & Count & 370 & 15 & 385 \\
\hline & & $\%$ & $96.1 \%$ & $3.9 \%$ & $100.0 \%$ \\
\hline
\end{tabular}

Table (11) Showing the fate of the distressed babies after delivery in the two groups

\begin{tabular}{|l|l|l|l|l|}
\hline & & Cases & Controls & Total \\
\hline \multirow{3}{*}{ Resuscitated and beside his mother } & Count & 1 & 7 & 8 \\
\hline \multirow{3}{*}{ Admitted to SCBU } & $\%$ & $12.5 \%$ & $87.5 \%$ & $100.0 \%$ \\
\hline \multirow{3}{*}{ Total } & Count & 3 & 4 & 7 \\
\cline { 2 - 6 } & $\%$ & $42.9 \%$ & $57.1 \%$ & $100.0 \%$ \\
\hline & Count & 4 & 11 & 15 \\
\cline { 2 - 6 } & $\%$ & $26.7 \%$ & $73.3 \%$ & $100.0 \%$ \\
\hline
\end{tabular}


Table (12) Compare the fresh and macerated still birth between two groups

\begin{tabular}{|c|c|c|c|c|c|}
\hline & & & Cases & Controls & Total \\
\hline \multirow[b]{3}{*}{ Still births } & \multirow[b]{2}{*}{ Fresh still birth } & Count & 5 & 15 & 20 \\
\hline & & $\%$ & $25.0 \%$ & $75.0 \%$ & $100.0 \%$ \\
\hline & Macerated still birth & $\%$ & $40.9 \%$ & $59.1 \%$ & $100.0 \%$ \\
\hline & \multirow[b]{2}{*}{ Total } & Count & 14 & 28 & 42 \\
\hline & & $\%$ & $33.3 \%$ & $66.7 \%$ & $100.0 \%$ \\
\hline
\end{tabular}

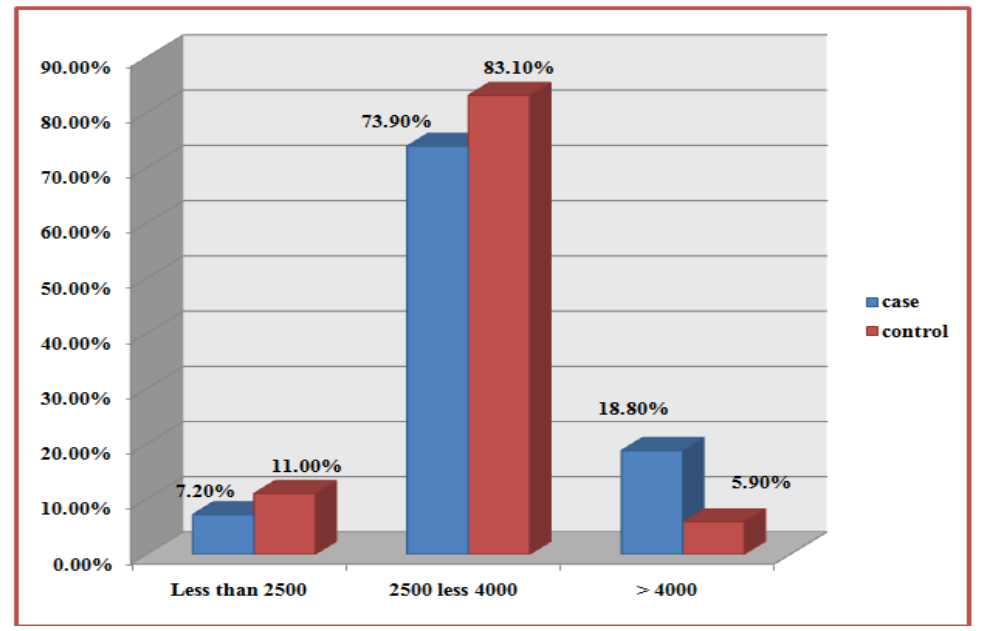

Figure(13) Showing the relation between parity and birth weight.

\section{Discussion}

Our aim in this study is to identify the common obstetrical problems of the grandmultipara (GMP), comparing it with multiparous woman.

In the age distribution of the cases, there were $38 \%$ above 35 years, while only $9.0 \%$ in the control highly significant $(\mathrm{p}=0.00)$. Advanced maternal age is associated with increase incidence of maternal complication like hypertension, diabetes mellitus, and high incidence of prenatal complication. This goes with Hench et al ${ }^{(11)}$ who found that the age of GMPs were significantly higher compared with control group which may explain the higher incidence of antenatal medical complication, but Maymon et al ${ }^{(13)}$ state that higher birth order remained an independent risk factor for peripartum complication after adjustment for maternal age.

Regarding socioeconomic status $48 \%$ of the cases were of low social class compared with $28.7 \%$ of the control which is statistically highly significant $(\mathrm{p}=0.00)$; this explain the increase in the incidence of anaemia among cases. Mor-Yosef et $\mathrm{al}^{(18)}$ found that the prenatal mortality and low birth weight were in correlation with low socioeconomic status but not with grandmultiparity. Another study by Bugg et al ${ }^{(9)}$ concludes that high socioeconomic backgrounds are not prerequisite for favorable result.

Hypertensive disorder of pregnancy are found to be $30.0 \%$ in GMP compared to $13.7 \%$ in control group which is statistically highly significant $(\mathrm{p}=0.00$ ), the essential hypertension was the commonest form of hypertensive disorder in the cases. This is explained by increased age of this group; the same finding as Vehaskari et al ${ }^{(12)}$, Maymon et a! ${ }^{(13)}$,and Al-Sibia, et al ${ }^{(14)}$.

Regarding DM and gestational DM $8.0 \%$ of the cases were found to have it, while $3.0 \%$ of the control have. It is statistically significant $(p=0.03)$, the higher incidence in GMP may be related to the age of the cases and this may explain the higher incidence of macrocosmic babies in this group, This agrees with Mwambingu FT retrospective studies ${ }^{(42)}$ in which there were higher incidence of DM, gestational DM and macrosomic babies in GMP. But Eidelman et al ${ }^{(4)}$ found no increase in the incidence of DM in GMP.

Anaemia was found to be $28.7 \%$ in GMPs group while $12.7 \%$ in the control which is statistically highly significant $(\mathrm{p}=0.00)$. The increased incidence reflect the low social class of GMP as well as short pregnancy interval this finding agree with most of the studies like Ogedengbe et $\mathrm{al}^{(10)}$, Bugg et al $\mathrm{l}^{(9)}$ and Al-Sibai et a $\mathrm{l}^{(14)}$.

The incidence of multiple pregnancy was $8.0 \%$ in GMPs.group compared to $3.3 \%$ in the multiplarous group which is statistically significant $(\mathrm{p}=0.03)$. Vehaskari et $\mathrm{al}^{(12)}$ found that no significant difference in the rate of multiple birth in GMPs.

The incidence of breech presentation was found to be $9.4 \%$ in the GMPs compared to $5.5 \%$ in the control which statistically, is highly significant $(\mathrm{p}=0.00)$, while transverse lie $(3.6 \%)$ in cases vs. $0.3 \%$ in the control group. This may be explained by the laxity of the abdominal muscle of the GMPs. This finding agrees 
with studies done by Babiniski et $\mathrm{al}^{(8)}$, Sibai et $\mathrm{al}^{(14)}$, Karl et $\mathrm{al}^{(22)}$ while Vehaskari et $\mathrm{al}^{(12)}$ found no significant increase of the incidence of breech presentation.

Preterm labour is $16.0 \%$ in cases and $12.7 \%$ in control groups which statistically is not significant. Resnick et $\mathrm{al}^{(11)}$ found no significant difference in the incidence of preterm labour among study groups while Sabai et $\mathrm{al}^{(14)}$ found increase incidence of preterm labour in GMPs group.

Regarding the relation between GMPs \& APH, the incidence of 39bruption placentae was $6.0 \%$ in GMPs, vs. $1.7 \%$ in control group. It is statistically significant $(p<0.05)$. This may be explained by increased incidence of hypertensive disorder and increased age in the GMPs group also it may be explained by increased incidence of anaemia especially due to folic acid deficiency. While the incidence of placenta previa is $2.7 \%$ in GMPs compared to $4.0 \%$ in the control group, Which is statistically significant $(p<0.05)$, this may be explained by the occurrence gynaecological problems like abortions and evacuations, past history of placenta previa, also the GMPs had higher incidence of multiple pregnancy, abnormal lie and presentations . Verhaskari et a ${ }^{(12)}$ found the frequency of 39 bruption placentae, placenta previa and retained placenta were significantly higher in GMPs, 39 bruption placentae is affected by both high parity and age, placenta previa is independent of age. Another study in Sudan done by Aziz FA found that there is higher rate of APH in GMPs group ${ }^{(32)}$ Abu-heja et $\mathrm{al}^{(17)}$ found in his study that there were no difference in the incidence of placental 39bruption and placenta previa among study group.

Regarding induction of labour there is a decreased incidence in GMPs $2.0 \%$ vs $11.0 \%$ it is highly significant $(\mathrm{p}=0.00)$. This may be explained by most of our protocols in hospital takes GMPs as relative contraindication for induction of labour especially (Prostaglandin).

Comparing the mode of deliveries between two groups we found that SVD is mode of delivery of most GMP $76.7 \%$ vs. $60.3 \%$ which statistically is highly significant $(p=0.02)$. There was significant decrease in the incidence of assisted vaginal delivery $6.0 \%$ vs. $12.0 \%$ in control group. $\mathrm{Em} \mathrm{C/S}$ was found to be reduced in GMP 17.3 vs. $22.3 \%$ in the control group which statistically is highly significant $(\mathrm{p}=0.02)$,

in indications of emergency caesarean section we found that:

$\mathrm{C} \mid \mathrm{S}$ due to failure to progress: $9.1 \%$ in GMPs while $90.9 \%$ were in the control group.

$\mathrm{C} \mid \mathrm{S}$ due to fetal distress: $27.3 \%$ in GMPs while $72.7 \%$ were in the control group.

$\mathrm{C} \mid \mathrm{S}$ due to obstructed labour: $14.3 \%$ in GMPs while $85.7 \%$ were in the control group.

$\mathrm{C} \mid \mathrm{S}$ due to abnormal lie: $83.3 \%$ in GMPs while $16.7 \%$ were in the control group.

C|S due to APH: $32.0 \%$ in GMPs while $68.0 \%$ were in the control group.

C|S due to PE: $16.7 \%$ in GMPs while $83.3 \%$ were in the control group.

C|S due to others causes: $40.0 \%$ in GMPs while $60.0 \%$ were in the control group.

This difference is statistically significant $\mathrm{P}=003$.

All this may be explained by tight perineum, anaemia in GMPs, sizable babies abnormal lie.

Vehaskari et al ${ }^{(12)}$ found that the incidence of operative delivery was roughly similar in GMPs and control group while C/S is lower among GMP. Another study Sipila $\mathrm{P}^{(19)}$ stated that GMPs had fewer C/S and vacuum extractor but more induction of labour than mother with low parity, also Karl et $\mathrm{al}^{(22)}$ found increase of rate of forceps delivery and C/S rate among GMP. In Lagos study was done and found increase incidence of obstructed labor in $\mathrm{GMPs}^{(10)}$.

The overall incidence of PPH was slightly less in GMP $8.7 \%$ vs $9.7 \%$ in the control group, but according to the causes, it was found that:

Uterine atony: $75.0 \%$ in GMPs, while $25.0 \%$ in the control group.

Genital tract injury : $19.0 \%$ in GMPs, while $81.0 \%$ in the control group.

Retained products : $14.3 \%$ in GMPs, while $85.7 \%$ in the control group.

Blood coagulpathy : $33.3 \%$ in GMPs, while $66.7 \%$ in the control group.

This difference is statistically significant. $\mathrm{P}<0.05$.

The main cause of PPH in GMPs was uterine atonia, On the other hand, the most common cause in multiparas were genital tract injuries, this may be explained by tight perineum, so the overall incidence of PPH is higher in control group. This agree with Babinzki et al(8). And the study done in Nigeria ${ }^{(28)}$ But another study done at a Wallowa university hospital showed no significant association between GMP and PPH but related to prolong $2^{\text {nd }}$ and $3^{\text {rd }}$ stage of labor and nonuse of oxytocics after vaginal delivery ${ }^{(30)}$. Therefore more studies needs to be done after adjusting these variables.

If we look at the causes of Genital tract injures in, we found that:

Ruptured uterus : $20.0 \%$ in the GMPs, while $80.0 \%$ in the control group. $25.0 \%$ of perineal tear: $10.0 \%$ in the GMPs, while $90.0 \%$ in the control group.

Extended episiotomy: $25.0 \%$ in the GMPs, while $75.0 \%$ in the control group.

Other causes: $50.0 \%$ in the GMPs, while $50.0 \%$ in the control group.

This difference is statistically not significant. $\mathrm{P}>0.05$. 
Comparison of maternal mortality between GMPS and multiparous women (safe parity) we found that: 1 maternal death in GMPs and 3inmultiparas $(0.7 \%$ vs $1.0 \%)$.Total maternal death rate $888.9 \backslash 100000$, while GMPs death rate 666.7\100000, and Multiparas death rate 1000\100000.MMR was higher in the control group, this reflects the increase incidence in the so called safe parity. Most of these deaths occurred during the delivery. This may be explained by increase in labour ward complication like obstructed labour, assisted vaginal delivery, Genital tract injures, Em C/S and bleeding from placenta previa in the control group. Also due to decreased attention by doctors in this group and decreased anticipation of complication, unlike in GMPs which considered as dangerous. This finding agrees with Ogedengbe et $\mathrm{al}^{(10)}$ who found maternal mortality rate 44,4/1000 amongst GMPs which is not significantly difference from general obstetrical population but two studies Vehaskari in Finland and the other Mikulondra $\mathrm{F}$ in Tunis found GMP had higher incidence of maternal mortality ${ }^{(12,35)}$.

In maternal deaths due to PPH, we found that $33.3 \%$ in GMP, and $66.7 \%$ in multiparas.

In maternal deaths due to Pulmonary embolism, we found that no cases in GMP, and all cases were occur in multiparas.

Regarding fetal outcome, condition of the babies after birth, and the fate of the distressed babies we found that: total still birth rate $98.1 \backslash 1000$, GMP still birth rate $101.4 \backslash 1000$, and multiparas still birth rate $96.6 \backslash 1000,(10.1 \%$ vs $10.0 \%)$. This difference is statistically not significant. $1.6 \%$ of the GMP babies had apgar score 4 to 6 while multiparas had 3.3\%. 1.6\% of the GMP babies had apgar score less than 3, while multiparas had $0.8 \%$. This difference is statistically not significant. $3.2 \%$ of the babies of the GMP were distressed, while $4.2 \%$ of the multiparas`s babies were.This difference is statistically not significant.

In the distressed babies we found that :

those resuscitated and beside their mothers: $12.5 \%$ were babies of the GMP, while $87.5 \%$ of the multiparas.

Those admitted to SCBU: $42.9 \%$ were babies of the GMP, while $57.1 \%$ of the multiparas.

This difference is statistically not significant.

Regarding the stillbirth we found that:

Fresh still birth babies, $25.0 \%$ of them from babies of the GMP, while $75.0 \%$ from control grup.

Macerated still birth, $40.9 \%$ of them from babies of the GMP, while $59.1 \%$ from control group.

This difference is statistically not significant.

Macerated still birth is common in GMPs this may be explained by being poor, anaemic, hypertensive, no antenatal follow up, and delayed at home hoping for home delivery. While fresh still birth is common in multiparas because of prolonged labour, increased obstructed labour, assisted, and operative delivery, also the believe that this is the safe parity so the team become relaxed, and this may reflect poor fetal monitoring in the labour ward, and the resuscitation team and facilities are not optimal.

Eidelman et $\mathrm{al}^{(4)}$ found that there is no difference between GMP and less parous ladies in still birth rate. This agree with G. J. Bugg et al. who found No significant differences in neonatal outcomes between the two groups ${ }^{[9]}$. MikulondraF, found the babies of GMPs group were severely asphyxiated at birth more frequently than those in the control group. ${ }^{,[36]}$ A Babinski, T Kerenyi found that low apgar scores significantly higher in grand multiparas than in multiparas although perinatal mortality remains low in these patients ${ }^{[8]}$.

Fetal macrosomia is another risk factor which is frequently found in GMPs, regarding the relationship between birth weight and parity, Macrosomic babies are significantly higher in GMPs groups ( $18.8 \%$ vs $5.9 \%$ in the control group). This may be explained by obesity, increased, maternal age and high incidence of DM in GMP group. This agrees with studies of Babiniski et $\mathrm{al}^{(8)}$ and Heija et $\mathrm{al}^{(17)}$,

on the other hand, the incidence of LBW is higher among the control group. (7.2\% in cases while $11.0 \%$ in the control group). The difference is statistically significant. This agreed with Kaplan B et al, and Eidelman AI et al who found lower rates of LBW infants among GMPs ${ }^{(11)}{ }^{(4)}$. This may be explained by that the women in this group -control group- are younger, less obese, and low rates of diabetes mellitus among them.

Nordin N.M. in his study Is grandmultiparity a significant risk factor in this new millennium, there was no significant difference in diabetes and glucose intolerance, ante partum and post partum hemorrhage. There was a significantly lower risk of first and second-degree perineal tear, and prolonged first stage of labor. There was a significant increased in induction of labor but there was no uterine rupture and no increased in Cesarean Section. There was an increased in meconium stain liquor but there was no increased risk of fetal distress. The fetal outcome was good and there was no tendency to macrosomic infants or shoulder dystocia. With adequate care, the maternal fetal outcome of grandmutiparous women is good and comparable to the multiparous women. Anemia is still common and patient education is important to overcome this problem ${ }^{(45)}$.

\section{Recommendations}

Most GMPs were of older age and poor socio-economic status so improvement in social class, health education, use of contraception and good antenatal and intrapartum monitoring are needed. 
Careful monitoring and anticipation of PPH in GMP with active Management of $3^{\text {rd }}$ stage of labour, and this should be the routine practice.

Efficient care for obstetric complications and effective referral system.

Resuscitation of babies should be done by well trained doctors with adequate facilities, and in suitable time.

Most of the maternal deaths occur during the delivery, so labour and delivery room should be covered by consultant on duty not on call only, and by well trained doctors, sisters and midwifes.

Excellent maternal and perinatal outcome is possible in grand multiparas with improvement of health care system. by doing so GMP can no longer be considered high risk.

Safe parity group should have more attention by doctors and labour ward staff, through increase anticipation of complications, so as to improve the outcome in this group.

\section{Conclusion}

Grand Multiparous women still had some complication mainly antenatal; they had significantly higher incidence of hypertension anaemia, DM, multiple pregnancy, malpresentation, and APH.

Most of GMP delivered normally with less use of instrumental delivery, Em C/S and overall less complicated labour.

The GMP delivered significantly macrosomic babies with significantly higher incidence of MSB.

Maternal deaths, Emergency caesarean section, PPH, and instrumental deliveries, genital tract injuries are increased in multiparas group, which was so called safe parity.

\section{Acknowledgement}

I would like to express my sincere gratitude to my supervisor:

Dr: Bashier G. M. ElImam .

Consultant Obstetrician and Gynecologist Soba University Hospital

Vice dean for Academic Affair Faculty of Medicine University of Khartoum

For his advices, valuable suggestions, and help.

I also thank Dr: A. A. Shiddo and Prof: Taha Umbali for their valuable advices.

I extend my thanks to Dr: Isamaldin M. Abdulla (community board), and Dr: Babikier M. Ali (MD community) M.O.H for their supports.

My best regards to my colleagues doctors, midwifes and nurses who helped me a lot during collecting the data, and finally thanks a lot to my patients who accepted to participate in this study .

\section{References}

[1]. B Solomons, the dangerous multgipara. Lancet 2 (1934), pp 8-11.

[2]. PA King, SJ Duthie and HK Ma, Grandmultiparity: a reappraisal of risks. Int. J Gynaecol Obstet 36 (1994), pp 13-16.

[3]. DS Seidman, Y Armor, D Roff, DK Stevenson and R Gale, Grand multiparity: an Jobstetric or neonatal risk factor?. Am J Obstet Gynecol 158 (1988), pp. 1034-1039. View Record in Scopus | Cited By in Scopus (25).

[4]. A Eidelman, R Kamar, MS Schimmel and B Eichanan, The Grandmultipara: is she still at risk?. Am J Obstet Gynecol 158 (1988), pp. 389-392. View Record in Scopus I Cited By in Scopus (29).

[5]. K Fuchs, BA Peretz, R Marcovic and I Timor-Tritsch, The grandmultipara: is it a problem? A review of 5,785 cases. Int $J$ Gynaecol Obstet 23 (1985), pp. 321-325. View Record in Scopus | Cited By in Scopus (40).

[6]. A Samueloff, S Mor-Yosef, D Seidman, R Rabinowitz, A Simon and J Schenker, Grand multiparity: a nationwide survey. Isr $J$ Med Sci 25 (1989), pp. 625-629. View Record in Scopus $\mid$ Cited By in Scopus (18).

[7]. Toohey JS, Keegan KA, Morgan MA, Francis J, Task S, deVeciana M. The "dangerous multipara": fact or fiction? Am J Obstet Gynecol 1995;172:683-6. Buy Now [Context Link].

[8]. Babinszki A, Kerenyi T, Torok O, Grazi V, Lapinski RH, Berkowitz RL. Perinatal outcome in grand and great-grand multiparity: effects of parity on obstetric risk factors. Am J Obstet Gynecol 1999;181:669-74. Buy Now [Context Link].

[9]. Bugg GJ, Atwal GS, Maresh M. Grandmultiparae in a modern setting. Br J Obstet Gynaecol 2002;109:249-53. [Context Link]

[10]. Ogedengbe OK, Ogunmokun AA Grandmultiparity in Lagos, Nigeria. Niger Postgrad Med J. 2003 Dec; 10(4):216-9.

[11]. Goldman GA, Kaplan B, Neri A, Hecht-Resnick R, Harel L, Ovadia J. The grand multipara. Eur J Obstet Gynecol Reprod Biol 1995;61:105-9. [Context Link].

[12]. Vehaskari A, Lahtinen J, Terho J Hazards of grand multiparity,: Ann Chir Gynaecol Fenn. 1968;57(4):476-84.

[13]. Maymon E, Ghezzi F, Shoham-Vardi I, Hershkowitz R, Franchi M, KatzM, Mazor M. Peripartum complications in grand multiparous women: para 6-9 versus para > or=10.: Eur J Obstet Gynecol Reprod Biol. 1998 Oct;81(1):21-5.

[14]. Al-sibai MH, Rahman MS, Rahman J. Obstetric problems in the grand multipara: a clinical study of 1330 cases. Obstetric problems in the grand multipara: a clinical study of 1330 cases. J Obstet Gynaecol (Lahore). 1987;8(2):135-8.

[15]. Ujah IA,Uqru-VA The trend of MMRin NigeriaEast Africa Med j. Aug:76[8],436-9.

[16]. Rizk DE, Khalfan M, Ezimokhai M. Obstetric outcome in grand multipara in the United Arab Emirates: a case control study. Arch Gynecol Obstet 2001;264:194-8. [Context Link].

[17]. Abu-Heija AT, Chalabi HE. Great grand multiparity: is it a risk? Int J Gynaecol Obstet 1997;59:213-6. [Context Link]

[18]. Mor-Yosef S, Seidman DS, Samueloff A, Schenker JG. The effects of the socioeconomic status on the perinatal outcome of grand multipara. Eur J Obstet Gynecol Reprod Biol 1990;36:117-23. [Context Link]

[19]. Sipila P, von Wendt L, Hartikainen-Sorri AL.

[20]. The grand multipara-still an obstetrical challenge? Arch Gynecol Obstet. 1990:247(4); 187-95. 
[21]. Shah P.S. Parity and low birth weight and preterm birth: A systematic review and meta-analyses (2010) Acta Obstetricia et Gynecologica Scandinavica, 89 (7), pp. 862-875.

[22]. Edith D. Gurewitsch MD, Elizabeth Johnson MS, Robert H. Allen PhD, Paul Diament PhD, Jill Fong MD, Daniel Weinstein MD, $\mathrm{PhD}$ and Frank A. Chervenak MD The descent curve of the grand multiparous woman.

[23]. Karl Fuchs, Bezalel-Alik Peretz, Rami Marcovici, Eitan Paldi and llan Timor-Tritsh The "Grand Multipara" — Is it a problem? Int J Gynaecol Obstet. 1985 Sep;23(4):321-6.

[24]. obstetric ten teachers .edited by Geoffrey V P Chamberlain .sixteen edition . P247.

[25]. Akulkumaran The effect of parity on uterine activity in labour. British journal of Obstet and Gyne September J984-vol.91p.843-848.

[26]. Dewhurst textbook of Obstetrics and Gynaecology, for postgraduates. edited by D. Keith Edmonds. Sixth edition 1999. P166-134-330.

[27]. an evidence -based text for MRCOG .edited by David M . Luesley, Philip N - Baker 2004. P131.

[28]. Selo-Ojeme DO ; Okonofua FE the risk factors for primary PPH A case control study Arch Gyecol obstet 1997;259[4] : 179-87.

[29]. Adetero. pregnancy and PPH in Nigerian women. West Africa J. Med 1992 jul -sep; U [3]; 172-8.

[30]. Vedat -A ,Hasan-B, Ismail-A. Rupture of uterus in labour . 1st J.M.Sci 1993-oct; 29[I0];634-43.

[31]. Selo-Ojeme DO ; Okonofua FE the risk factors for primary P.PH A case control study Arch Gyecol obstet 1997;259[4] : 179-87.

[32]. Mwambingu FT; AI Meshari AA, Akiel A. : The problem of grandmultiparity in current obstetric practice. Int J Gynaecol Obstet 1988 Jun;26(3):355-9.

[33]. Aziz FA. Pregnancy and labor of grand mult iparous Sudanese women. Int J Gynaecol Obstet. 1980 Sep-Oct;18(2):144-6.

[34]. 33-Simonsen SM, Lyon JL, Alder SC, Varner MW Effect of grand multipariry on intrapartum and newborn complications in young women.Obstet Gynecol. 2005 Sep;106(3):444-5.

[35]. A. Bianco, J. Stone, L. Lynch, R. Lapinski, G. Berkowitz and R.L. Berkowitz, Pregnancy outcome at age 40 and older. Obstet Gynecol 87 (1996), pp. 917-922.

[36]. MikuJandra F; Perisa M; Merlak 1; Kimer M; Sikic D, Jerkovic J Pregnancy, labor and the neonate in pluriparas and multiparas] Jugosl Ginekol Perinatol 1990 May-Aug;30(3-4):83-6 52.

[37]. Mikulondra-F ,Persia-M ,Mertak-I GMP-an obstetric problem. Zentrabl-gynecol 1992,114[10]:491-6.

[38]. Tsu VD Postpartum haemorrhage in Zimbabwe : a risk factors analysis Br J Obstet Gynaecol 1993 Apr; I00[4] :327-33.

[39]. Sudan census 2008.

[40]. Tanbo TG, Bungum L. The grand multipara: maternal and neonatal complications. Acta Obstet Gynecol Scand 1987;66:53-6. [Context Link].

[41]. Bai J, Wong FW, Bauman A, Mohsin M. Parity and pregnancy outcomes. Am J Obstet Gynecol 2002;186:274-8. Buy Now [Context Link].

[42]. Roopnarinesingh S, Ramsewak S, Reddy S Complications of grand multiparity. West Indian Med J. 1988 Dec;37(4);222-5.

[43]. Pregnancy complications of gradmultiparity at a rural setting of South Africa Hoque, M., Hoque, E., Kader, S.B. Iranian Journal of Reproductive Medicine 6 (1), pp. 25-31-2008.

[44]. $\quad$ Grandmultiparas in modern obstetrics (2006) American Journal of Perinatology, 23 (6), pp. 345-349.

[45]. Iftikhar S., Shams-Un-Nisa, Sheikh M.A., Malik A.M. Fetomaternal outcome in women with grandmultiparity and multiparity (2010) Medical Forum Monthly, 21 (4), pp. 50-54.

[46]. Nordin N.M., Fen C.K., Isa S., Symonds E.M. Is grandmultiparity a significant risk factor in this new millennium? (2006) Malaysian Journal of Medical Sciences, 13 (2), pp. 52-60. 